\title{
Force Analysis of Double-Tube Buckling Restrained Braces with Contact-Ring
}

\author{
Zhan Zhong Yin* and Xiu Li Wang
}

School of Civil Engineering, Lanzhou University of Technology, Lanzhou 730050, China

\begin{abstract}
Double-tube buckling restrained braces with contact ring is a new buckling-restrained brace (BRBs), and is a refinement on double-tube buckling restrained braces. Based on the theory of the finite element method, the finite element entity model of Double-Tube Buckling Restrained Brace with Contact-Ring has been built. The Double-Tube Buckling Restrained Brace is systematically analyzed and computed. The analysis results indicate that this kind of buckling restrained brace has good dissipation energy capacity and restoring force characteristics, and can overcome the difficulty in connection.
\end{abstract}

Keywords: Buckling Restrained Braces, Hysteretic Performance Analysis, The Finite Element Analysis.

\section{INTRODUCTION}

In recent years, the scholars both from Japan and America have actively engaged in the research and application of buckling-restrained braces (BRBs) [1-3]. In the traditional steel frame structure, there are central bracing and eccentric bracing to increase the ability of lateral stiffness.

However, the frame structure of central bracing will be probably buckled and be out of operation when there are weak or strong earthquake actions, because the buckling of this bracing can not effectively dissipate the energy, which leads to decline of seismic performance [4]. In order to resolve this problem, the scholars both at home and abroad had developed a brace which can not be buckled. It is called BRBs (Buckling Restrained Braces) [5, 6]. This article, based on past research, points out the way to improve the behavior of Double-Tube Buckling Restrained Braces by ameliorating the construction of inner tube, namely, setting one or several Contact Rings in the inner tube in order to supply a lateral restraint for the inner tube $[7,8]$.

\section{THE GEOMETRICAL PARAMETER OF MEMBER}

My research had initially demonstrated that double-tube braces with the reasonable design have better energy dissipation capacity and have the same effect of tension and pressure of member. In order to overcome the shortcoming of the member, this article puts forward setting a series of short steel tube, contact rings (see Fig. 1), between inner tube and outer tube. This designing can make the two ends and central part of inner tube and outer tube closely combined,

*Address correspondence to this author at the School of Civil Engineering, Lanzhou University of Technology, Lanzhou 730050, China;

Tel: +86-931-2973784; Fax: +86-931-2976327;

E-mail: yinzhanzhong-1@163.com, yinzhanzhong@lut.cn which can not only solve the problem of clearance, but improve the capability of carrying with a lateral bracing supplied by the contract rings.

This paper has conducted analogous analysis of the finite element on 6 members. The geometrical size and section parameter of all members are shown in the following Table 1.

\section{FINITE ELEMENT MODEL}

The author adopts the Finite Element Analysis software (ANSYS) to analyze the braces and employs the SOLID45 to build a model of tube, inner tube and outer tube of members (see Fig. 2). In this model, there is a large room of contact area between inner tube and outer tube. By using TARGE170 and CONTA174, the contact area has been combined fictitiously. According to Von Mises, the principles of yielding and the related rules of plasticity flowing, it is concluded that the material will have the problem of plastic displacement and the direction of plastic strain. The calculation should take the characteristics of displacement of member and the movement of contact area into consideration, because the displacement of structure will cause nonlinear structure. The comprehensive yield strength of member inner tube is $235 \mathrm{Mpa}$. The yield strenghth of outer tube is $235 \mathrm{Mpa}$, employing steel Q235 with 0.3 elastic modulus.

\section{THE ANALYSIS OF THE RELATIONSHIP OF LOAD AND DISPLACEMENT}

In order to get more reliable result of settlement, initial defections were taken into account, such as initial bending. Based on characteristic value buckle analysis method of finite elements theory, initial bending of member was obtained. The value of initial bending was one-in-a-thousand or three-in-a-thousand times wider than initial bending. 

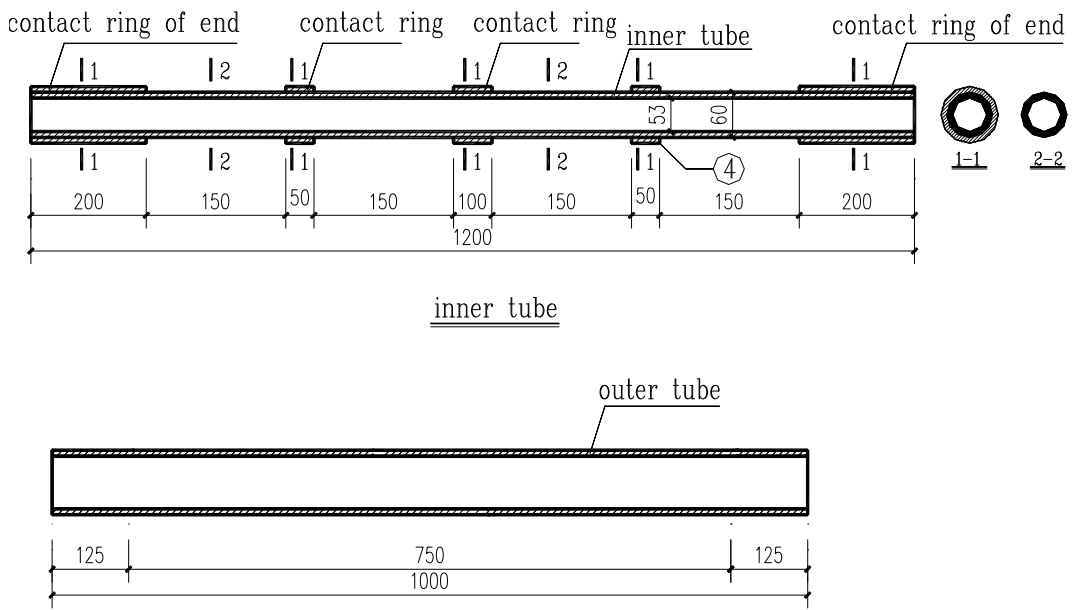

$\underline{\underline{\text { outer tube }}}$

Fig. (1). The Figure of Constructional Detail.

Table1. The Geometrical Size and Section Parameter of All Members [mm]

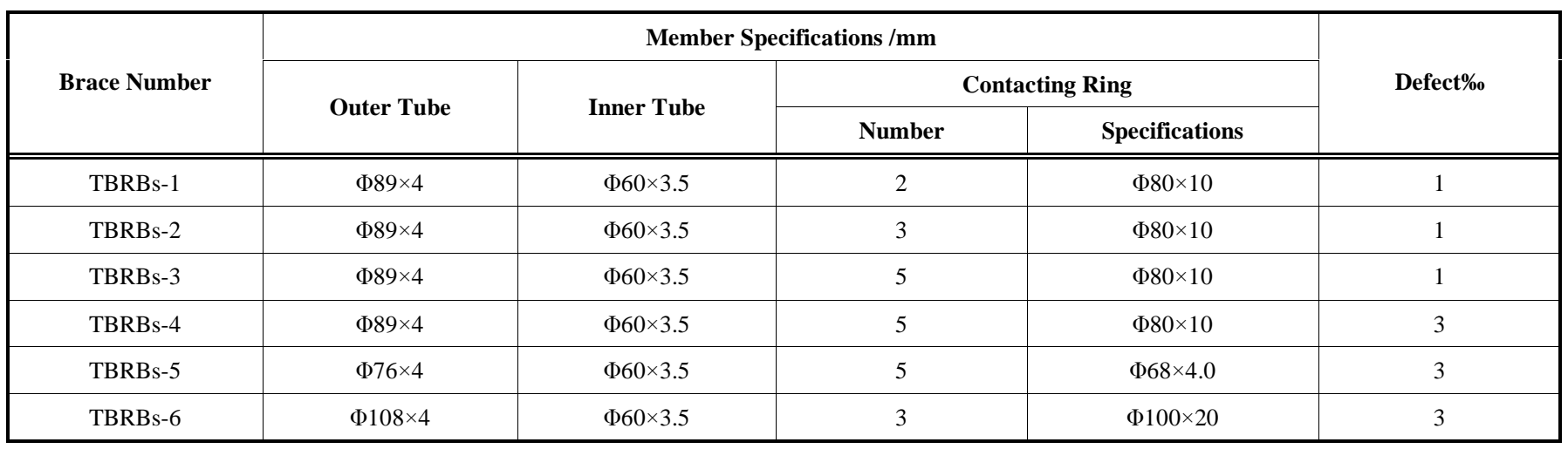

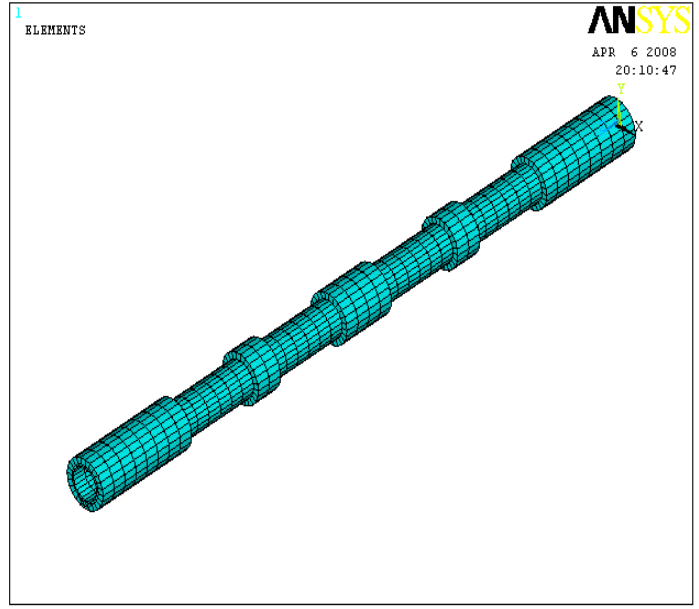

Fig. (2). The Figure of finite element model.

As can be seen from the figure of stress (see Fig. 3), when axial displacement of inner tube of TBRBs reached $1 \sim 2 \mathrm{~mm}$, the stress of inner tube reached the yield point. From this phenomenon we can see that inner tube BRBs were starting to dissipated energy. Combining with loaddisplacement curve (see Fig. 4), the Buckling-Restrained Braces (BRBs) show the same load-deformation behavior in both compression and tension, and ideal elastic-plastic model was drawn. And elastic-plastic model become perfect with the increase of number of contacting ring. Load-displacement curve from Fig. (4a) suggests that plastic segment of curve had significant volatility. This is primarily caused by limited numbers of contacting ring. These results imply that the capacity of BRBs with contact ring to absorb energy increased with the increase of number of contacting ring.

(1) Fig. (4) shows that the initial stiffness of TBRBs-3 is the largest one and that of TBRBs- 1 and TBRBs- 2 are smaller. The reason is that the number of contact ring of TBRBs-3 is the largest one. Due to the effect of contact rings, the initial stiffness of member depends on the stiffness of constraining tubes. (2) Fig. (4) shows that there is a little fluctuation on the curves after the yield of three members. The curve of TBRBs- 1 and TBRBs- 2 has fluctuation when the displacement reaches to $8 \sim 12 \mathrm{~mm}$, because the relatively large clearance leads to the bulking of inner-tube in the later period of loading. When the sideways of inner-tube reaches to the clearance, its constraining force will function and the bearing capacity of members will be renewed. But, the curves of MBRBs3 have no fluctuation. Therefore, the effect of clearance can not be neglected, which is also demonstrated in Fig. 


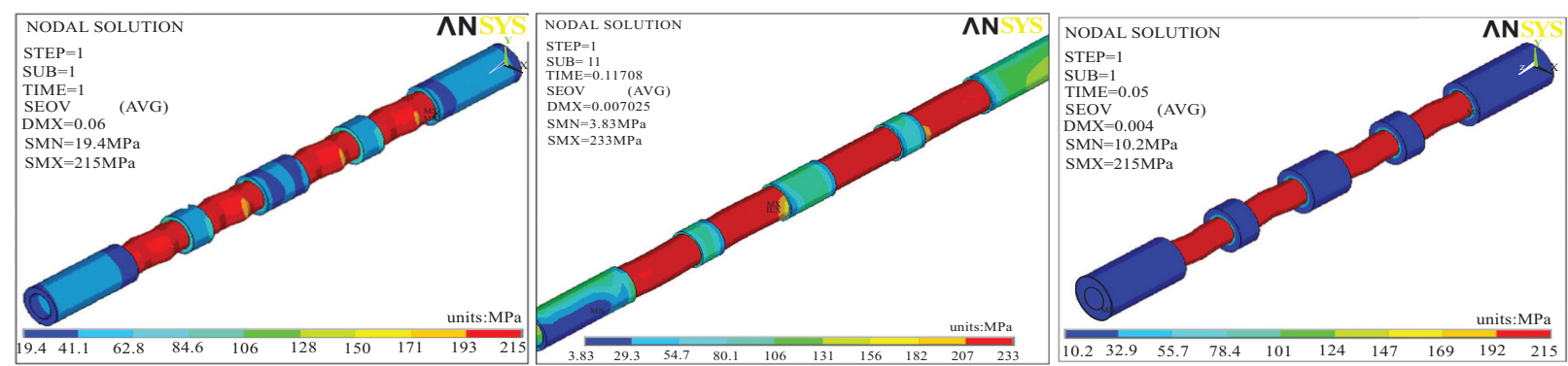

( a ) TBRBs-4 stress figure ( b ) TBRBs-5 stress figure ( c ) TBRBs-6 stress figure

Fig. (3). Stress figure.

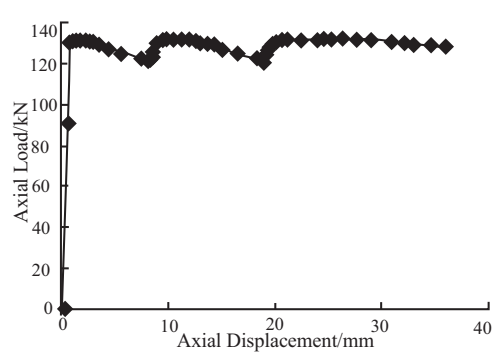

( a ) TBRBs-1

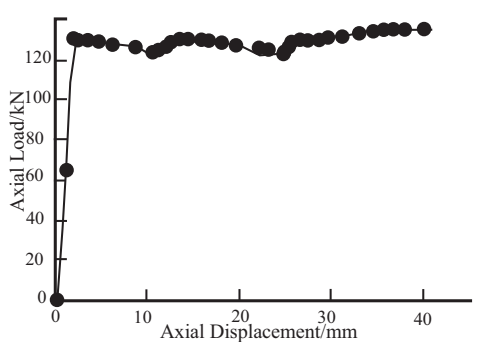

( b ) TBRBs-2

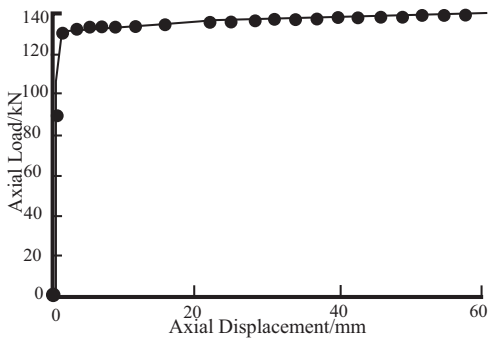

( c ) TBRBs-3

Fig. (4). Axial load-displacement curve.

(4c). (3) From the development tendency of curves, there are two stages: The curves of five members are the same before yielding and they are the relatively ideal linear stage. The curves of TBRBs-3 is relatively smooth from the point of yielding to $26 \mathrm{~mm}$, which is the linearintensified stage, a elastoplastic stage that the bearing capability has no increase but the displacement is increasing.

Maximum lateral displacement of inner tube of all TBRBs reached clearance distance between inner tube and outer tube respectively. It means that deformation of inner tube was constrained on outer. And according to Fig. (3), the larger the clearance distance was, the larger the deformation was. But when the clearance distance was too small, failure which is caused by local buckling of inner tube was possible.

Moreover, it was clear that minimum strain of BRBs with contact ring reached $2.25 \%$, and maximum strain of that reached $16.67 \%$. This value exceeded maximum strain of yielding stage in ideal elastoplastic model. This means deformation capacity of inner tube was very good. It was that BRBs can absorb higher energy under earthquake action, so the safety of structure was enhanced.

\section{HYSTERETIC CHARACTERISTIC ANALYSIS}

The earthquake is manifested itself with frequent movement of ground back and forth. Generally, the relationship between inner forces and displacement of members shows the hysteretic curve under the cyclic loading. The hysteretic curve is a curved line of load and displacement, resulted from a cyclic loading. The skeletonframe curve is the envelope curve formed by linking the peak points of each hysteretic curve that have shown in the experiments of amplitude-displacement loading. The area of hysteretic curve represents the energy dissipation capability of members. The bigger the area is, the stronger the energy dissipation capability is. Through comparing with the hysteretic curves of various members, it concludes that the shape of hysteretic curve can reflect, from a macro 
Table 2. The Calculation Results

\begin{tabular}{|c|c|c|c|c|}
\hline Brace Number & Stiffness of Outer tube $\left[\mathbf{k N m}^{\mathbf{2}}\right]$ & Ultimate Load Pu [ kN] & Clearance /mm & Comprehensive Modulus $\boldsymbol{\eta}$ \\
\hline \hline TBRBs-4 & 196.2604 & 141.135 & 10 & 19.63 \\
\hline TBRBs-5 & 121.1486 & 135.328 & 4 & 30.29 \\
\hline TBRBs-6 & 364.517 & 132.427 & 20 & 18.22 \\
\hline
\end{tabular}

perspective, the operating principles of seismic resistance of members [9].

Under the circumstances of repetitive application of load, the strength and stiffness of members may be degraded. If the peak points of displacement is keeping unchanged with the repetitive application of load and then the peak of load is declining with the increase of cycles, this phenomenon is called strength degradation. If the peak of load is keeping unchanged with the repetitive application of load and then the peak points of displacement is growing with the increase of cycles, this phenomenon is called stiffness degradation. The damage is resulted from accumulative damage. The degree of degradation varies with materials and their disruptive behavior. The characteristic of degradation concerning brittle fracture is more salient than that concerning ductility fracture.

To further discuss the emerge-consuming capability of BRBs with contact ring, the experiments had been conducted by repetitively loading the members listed in Fig. (1) and had gotten the curved line in Fig. (3). In addition, it also discussed the variation of hysteretic curve behavior with quantities of contact rings, different defects and stiffness of outer tube.

\subsection{The Effect of Restraining Stiffness and Clearance}

According to unidirectional load, the restraining stiffness and clearance have different effects on carrying capacity of structure. Here, the effect of restraining stiffness and clearance has been analyzed by comprehensive modulus $\eta$ of restraining stiffness. The inner tubes of TBRBs-4、TBRBs5 and TBRBs- 6 are $\Phi 68 \times 3.5$, with the same parameters but different restraining stiffness and clearance (See Table 2). The following discussion will focus on the effects of restraining stiffness and clearance on hysteretic behavior of members through analyzing hysteretic curve (Fig. 5d, f, g).

1) Given the degree of fullness of hysteretic curve, TBRBs4 has the largest degree of fullness. TBRBs-5 and TBRBs-6 have little differences in fullness, which shows

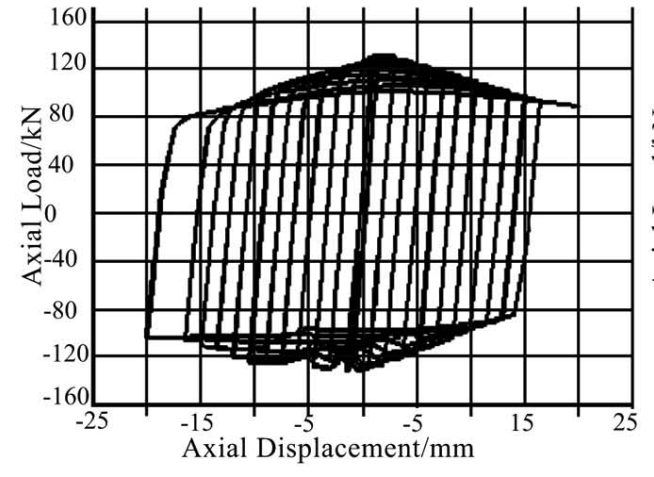

(a) TBRBs-1(1\%o)

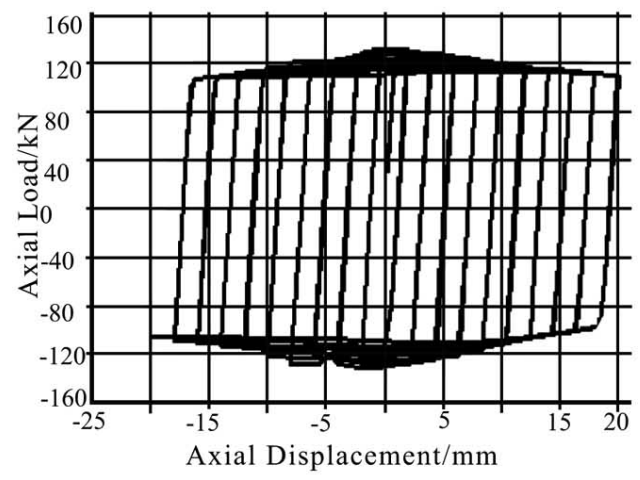

(c) TBRBs-3(1\%o)

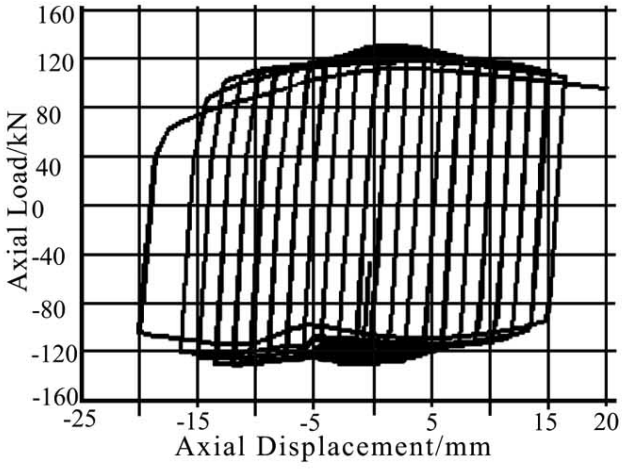

(b) TBRBs-2(1\%o)

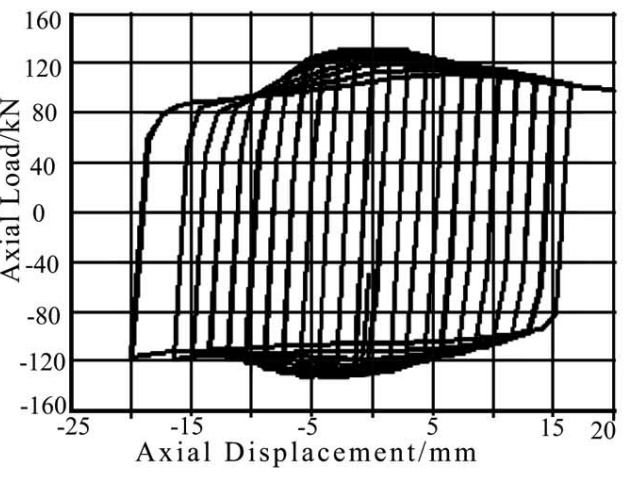

(d) TBRBs-4(3\%) 
Fig. (4). contd....

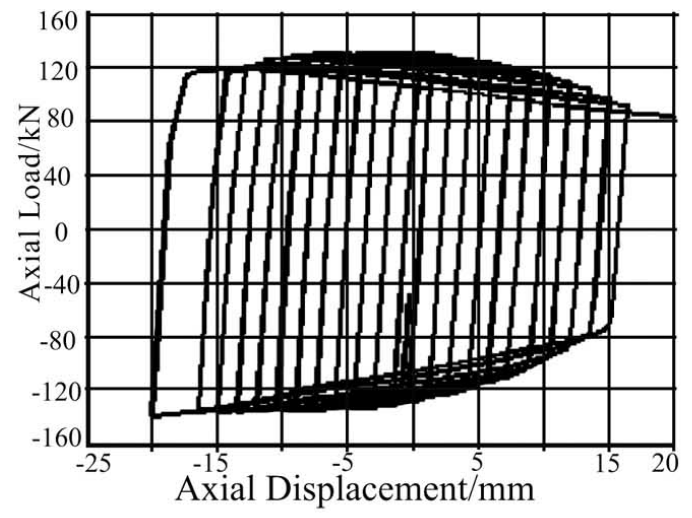

(f) TBRBs-5 (3\%)

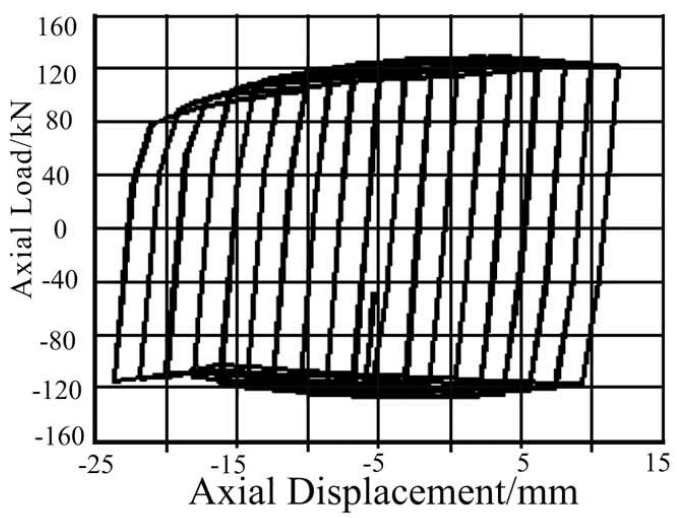

(g) TBRBs-6 (3\%)

Fig. (5). The hysteretic curve of element.

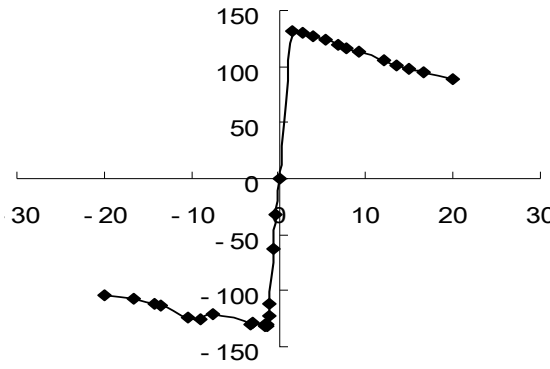

(a) TBRBs-1

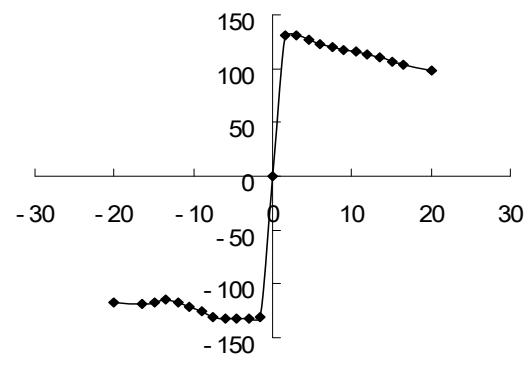

(b) TBRBs-4

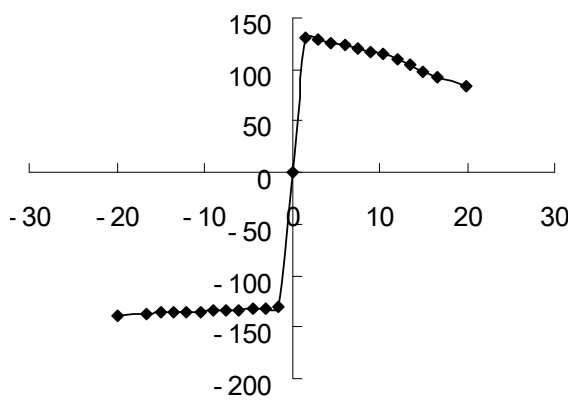

(c) TBRBs-5

Fig. (6). The skeleton curves..

the energy dissipation capacity of these members has no differences. In terms of stiffness and clearance, TBRBs-4 has the middle level compared with TBRBs-5 and TBRBs6. It shows that the effect of intensifying stiffness can be partly counteracted by the effect of widening clearance. Therefore, the best hysteretic behavior can only be achieved with the appropriate proportion of clearance and stiffness.

2) Considering the trend of hysteretic curves, TBRBs-4 has more symmetrical and stable curves. The stiffness degradation of TBRs-7 is salient and its degree of degradation varies with tension and compression. The stiffness degradation of TBRBs-5 is salient when there is tension and the stiffness degradation of TBRBs- 6 is distinct when there is compression. The reason can be evident in Fig. (3). The major reason is that TBRBs-5 has the contact rings with less wafery thickness. When compression load reaches a certain degree, the inner tube will be deformed partly. However, when the value of displacement reached the thickness of contact rings, displacement are restrained by outer tube. As a result, the degradation of carrying capacity is little under the compression. On the contrary, the carrying capacity will decline when the area of displacement that is equivalent to unloading is large under compression. However, the thicker contact rings of TBRBs-6, together with the original bend, leads to much more damage of inner tube. In other words, the carrying capacity of TBRBs- 6 will decline when the load reaches the extreme and can not maintain balance. These are two opposite ways of degradation in term of the difference of restraining stiffness and clearance.

\subsection{The Skeleton Curves}

The earthquake is manifested itself with frequent movement of ground back and forth. Under the cyclic loading, the inner force and displacement of members manifest hysteretic phenomenon. The load-displacement curve formed by the homotaxial member under the cyclic loading is called homotaxial hysteretic curves. The hysteretic circuitry formed by linking peak points of the first loading curve with the peak points of every hysteretic curve is called skeleton curve. The hysteretic curve and skeleton curve are called by a joint name restoring force curve. The restoring force represents the restoration capacity of members after unloading. Therefore, the restoring force curve represents the relationship between restoring force and displacement, namely, the displacement process of members under the cyclic loading. The hysteretic curves of TBRBs-1, TBRBs-4, TBRBs- 5 has been chosen and formed a skeleton curve (Fig. 6, $\mathrm{x}$-axis is displacement $/ \mathrm{mm}$; $\mathrm{y}$-axis is load/kN). This curve 
shows that the load-displacement curve of members have the same form as unidriectional loading under the pressure, but the carrying capacity of member will decline when there is tension, which is resulted from the stiffness degradation.

\section{CONCLUSIONS}

Through analysis of double-tube buckling restrained braces with contact ring based on the finite element method, the paper discusses its restoring force characteristics and the law that energy dissipation capacity varies with restraining stiffness, double-tube clearance, original defects and quantities of contact rings. The conclusions are as following:

(1) The double-tube buckling restrained braces with contact ring has better capacity of energy dissipation, and there are basically same performance under both compression and tension. Sometimes, it has better stability of behavior of compression.

(2) The connection of double-tube buckling restrained braces with contact ring is much more reliable and convenient with no problem of damage in connection part.

(3) Energy dissipation and ductility of double-tube buckling restrained braces with contact ring are better under cyclic loading. But the strength degradation is salient when there is tension. And when there is compression, the stiffness degradation is obvious while the strength has no change.

(4) The quantities of contact rings, restraining stiffness and clearance have effects on hysteretic behavior. The increase of contact rings can improve hysteretic behavior. The stronger restraining stiffness and more proper clearance will make hysteretic curve performance better.

(5) From the perspective of skeleton curve, the skeleton curve of double-tube buckling restrained braces with contact ring has the same shape as unidriectional loading under the compression, but the stiffness is degrading under the tension.

\section{ACKNOWLEDGEMENTS}

This research is supported in part by National NSFC(Natural Science Foundation of China)(50678078), Foundation of Gansu Province,China (1010RJZA038) and Alumni Foundation of Civil Enginneering 77, Lanzhou University of Technology.

\section{REFERENCES}

[1] K. Thomopoulos and E. Koltsakis, "Connections of CHS concretefilled diagonals of X-bracings", Journal of Constructional Steel Research, vol. 59, pp. 665-678, May 2003.

[2] Yamaguchi M., Yamada, and Matsumoto Y., Murase J , "FullScale Shaking Table Test of Damage Tolerant Structure with a Buckling Restrained Brace", Journal of structural and construction engineering, vol. 55, pp189-196, August 2002.

[3] Kim J and Seo Y, "Seismic Struchires design of loin-rise steel frames unth buckling-restrained braces", Engineering Structures vol. 26, pp. 543-551, May 2004. (in Chinese)

[4] Wang Xiu-li, CHEN Xiang-yong, YIN Zhan-zhong, "An Analysis of Seismic Vibration Reduction of K6 Spherical Latticed Shell by Means of Buckling-Restrained Braces", Journal of Gansu Sciences, vol. 19, pp. 122-126, January 2007. (in Chinese)

[5] Uang Chia-ming, NAKASHI MAM asayoshi, "The Practice and Research Development of Buckling Restrained Braced Frames(II)", Progress in Steel Building Structures, vol. 7, pp. 1-11, February 2005. (in Chinese)

[6] Tsai Keh-Chyuan, Hwang Yean-chih, Weng Chung-shing, "Seismic Performance and Applications of Double-Tube Buckling Restrained Braces", Progress in Steel Building Structures. vol. 7, pp. 1-8, March 2005. (in Chinese)

[7] Wang Xiu-li, Chen Ming, "FEM analysis of a kind of bucklingrestrained brace fit in space truss structure", Journal of Lanzhou University of Technology, vol. 33, pp. 124-127, June 2007. (in Chinese)

[8] Yin Zhan-zhong, Wang Xiu-li, LI Xiao-dong, "Finite element analysis of double-steel-tube buckling restricting braces with contact-ring", Journal of Lanzhou University of Technology, vol. 32, pp. 122-126, October 2008. (in Chinese)

[9] Cao Zi and Xue Suduo, Sesimic Analysis and Design of Spetial Structures. Beijing: Science Press, 2005. (in Chinese)

Received: July 26, 2010

Revised: November 21, 2010

Accepted: January 04, 2011

(C) Yin and Wang; Licensee Bentham Open.

This is an open access article licensed under the terms of the Creative Commons Attribution Non-Commercial License (http://creativecommons.org/licenses/_by-nc/3.0/) which permits unrestricted, non-commercial use, distribution and reproduction in any medium, provided the work is properly cited. 